\title{
A preliminary study of the degradation of selected commercial packaging materials in compost and aqueous environments
}

\author{
Marta T. Musioł ${ }^{1}$, Joanna Rydz ${ }^{1}$, Wanda J. Sikorska1, Piotr R. Rychter², Marek M. Kowalczuk ${ }^{1,2}$ \\ ${ }^{1}$ Polish Academy of Sciences, Centre of Polymer and Carbon Materials, M. C. Skłodowskiej 34, 41-819 Zabrze, Poland, \\ e-mail: m.musiol@cmpw-pan.edu.pl \\ ${ }^{2}$ Jan Dtugosz University, Institute of Chemistry, Environment Protection and Biotechnology, Armii Krajowej 13/15, \\ 42-200 Częstochowa, Poland
}

\begin{abstract}
The paper presents the results of the degradation of two commercial packaging materials CONS-PET and BioPlaneta in the compost and distilled water at $70^{\circ} \mathrm{C}$. The materials containing polylactide (PLA), CONSPET 13\% and BioPlaneta 20\%, aliphatic-aromatic copolyester terephthalic acid/adipic acid/1,4-butanediol (BTA) and commercial additives degraded under the industrial composting conditions (composting pile or container) and in distilled water at $70^{\circ} \mathrm{C}$ in the laboratory holding oven. Distilled water provided the conditions for the hydrolytic (abiotic) degradation of the materials. Weight loss, changes of molecular weight, dispersity monitored via the GPC technique and the macroscopic surface changes of the tested materials were monitored during the experiments. The investigated systems show similar trends of degradation, however on the last day of the incubation the decrease of the molecular weight was higher in water than under the industrial composting conditions. The results indicate that commercial packaging materials can be degraded both while composting ((bio)degradation) and during the incubation in distilled water at $70^{\circ} \mathrm{C}$ (abiotic hydrolysis).
\end{abstract}

Keywords: Polylactide, PLA, aliphatic-aromatic copolyester, BTA, (bio)degradation, industrial composting pile, container system, hydrolytic degradation.

\section{INTRODUCTION}

The increasing problems with domestic waste, particularly with plastics, demanded new solutions in the production of packaging materials. A new class of polymers specially designed to be biodegradable has been investigated for more than 20 years. A number of biodegradable plastics have been successfully developed over the past few years to meet specific demands in various fields, e.g. in agriculture and packaging industries. Recently several of such materials have entered the market. Polyesters such as poly(L-lactide) and aliphatic-aromatic copolyester terephtalic acid/adipic acid/1,4-butanediol, BTA belong to the best understood and most extensively studied plastics with regard to biodegradation. The materials have attracted great attention in recent years due to their excellent properties, which gives rise to potential applications in various commercial areas. Additionally, the processing properties of the polyesters are similar to those of more conventional thermoplastics, which enables them to be used in large-scale commercial processing like injection, extruding-blowing and thermomoulding in order to produce materials with the required mechanical properties, strong enough for industrial packaging or fibers for textile applications. The degradation of polyesters in biological environments, including the anaerobic and aerobic conditions, activated sludge, public waste-fields and composting facilities, results from an enzymatic attack or from simple hydrolysis, or both ${ }^{\mathbf{1}-\mathbf{3}}$. Under specific conditions encountered in the compost, these materials may undergo degradation with the aid of specific enzymes formed by microorganisms such as bacteria or fungi ${ }^{4-6}$.

The only pilot project in the world for the marketing and recycling of the compostable packaging made from biodegradable polymers was conducted jointly by the industry and the Federal Ministry of Consumer Protection,
Food and Agriculture in Kassel, Germany (2001 - 2002). At present a similar program is being carried out in Zabrze, but on a smaller scale ${ }^{7}$. In the city of Zabrze, where the system of waste segregation at source was introduced, the necessary infrastructure for segregating waste, raw material recycling and selected organic waste composting, was created. So far, several thousand households have decided to participate in the challenge program. The collected domestic waste with the fully biodegradable bags made of maize starch are being composted along with branches, leaves and grass in the container system at the average controlled temperature.

In the literature the degradation behaviour of PLA and BTA in selected natural environments as well as under composting conditions was presented ${ }^{\mathbf{3}, \mathbf{8 , 9}}$. The aim of the study is to determine the degradability of two selected packaging materials in compost ((bio)degradation) and in distilled water at $70^{\circ} \mathrm{C}$ (abiotic hydrolytic degradation).

\section{EXPERIMENTAL}

\section{Materials}

The incubation under industrial composting conditions and hydrolytic degradation of the commercial biodegradable bags (CONS-PET and BioPlaneta) were investigated. The materials were kindly provided by CONS-PET Agency (CONS-PET) and Green Planet Investment s.r.o. (BioPlaneta). These materials containing polylactide (PLA), CONS-PET $13 \%$ and BioPlaneta 20\%, aliphaticaromatic copolyester terephthalic acid/adipic acid/1,4butanediol (BTA) and commercial additives.

\section{Experimental procedures and analyses}

The cages with polymeric materials, Figure 1, were placed in a composting pile containing $40 \%$ leaves, $30 \%$ 
branches and $30 \%$ grass, and in a container system consisting of $18 \%$ leaves, $22 \%$ branches, $23 \%$ grass and $37 \%$ collected domestic waste from selected segregation, Figure 2 , at the depth of one meter under the surface for 1 and 3 weeks.

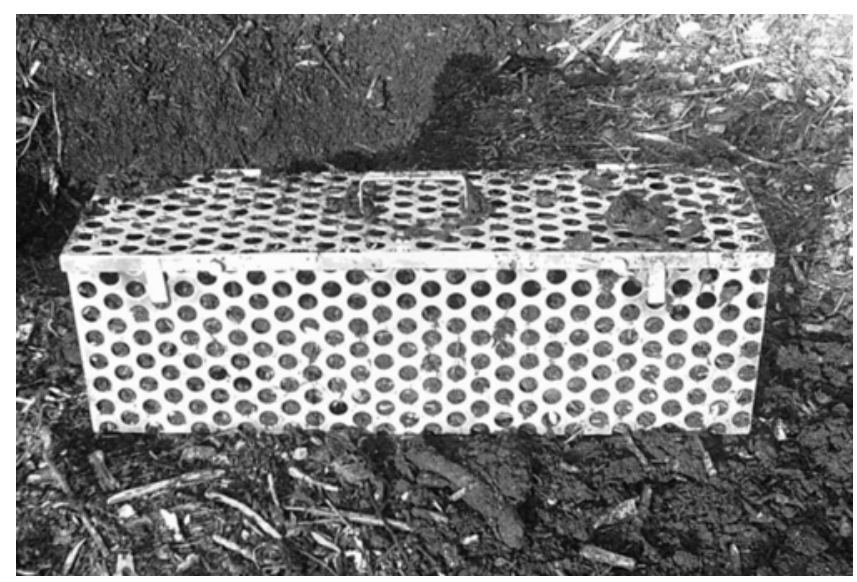

Figure 1. Cage with the samples at the research site in the Sorting Station and Composting Plants in Zabrze

a)

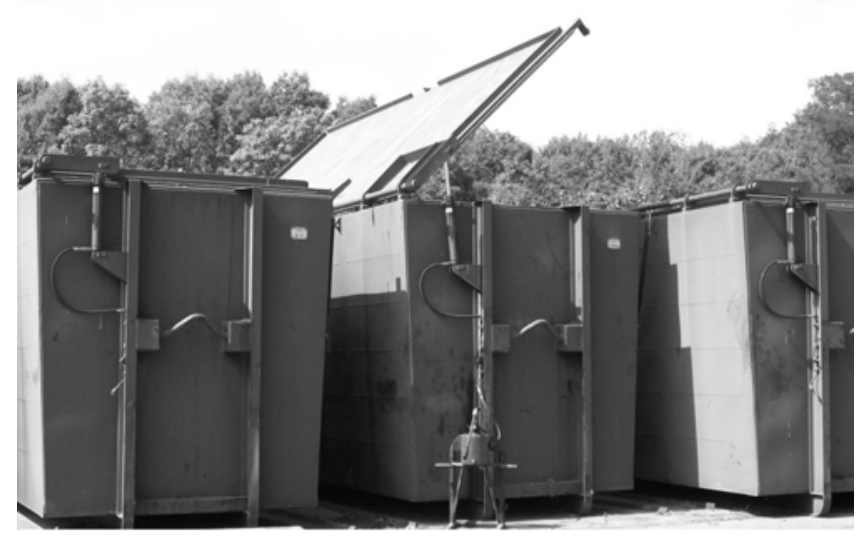

b)

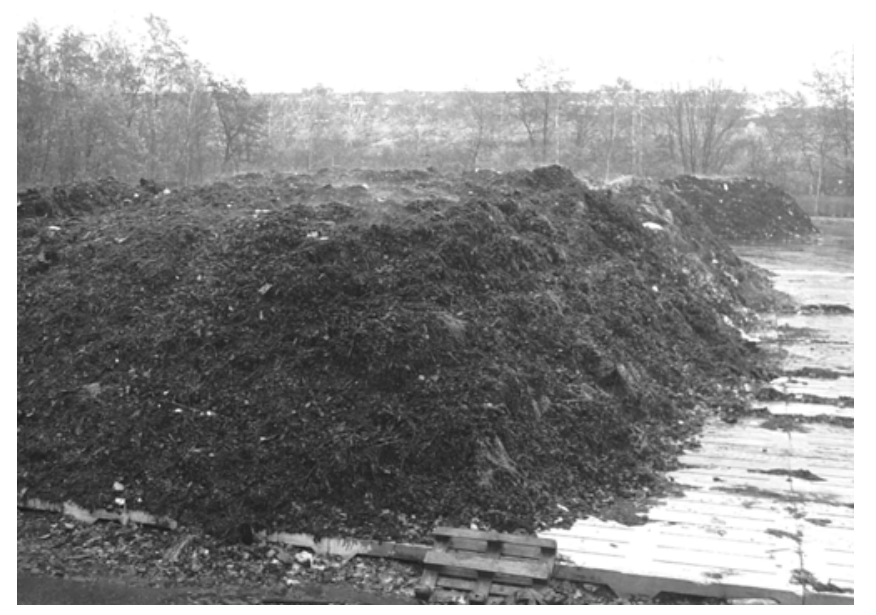

Figure 2. Research site in the Sorting Station and Composting Plants in Zabrze a) container system, b) composting pile

The average temperature amounted to $64^{\circ} \mathrm{C}$ for the composting pile and $60^{\circ} \mathrm{C}$ for the container system.
The incubation in the composting pile was performed at average $\mathrm{pH}=6.9$ measured at the research site by the Hanna pH-meter HI 99141. At the same time, the course of hydrolysis in water at $70^{\circ} \mathrm{C}$ of the same polymeric materials was investigated for four weeks. The $\mathrm{pH}$ of the solutions after incubation at the temperature $70^{\circ} \mathrm{C}$ in the laboratory holding oven was measured by the Mettler Toledo SevenMulti Modular Meter Systems, METTLER TOLEDO Meter with $\mathrm{pH}$ and Conductivity Expansion Units and Inlab 413 and 730 Electrodes. The obtained results are present in Table 1.

Table 1. $\mathrm{pH}$ of the solutions after incubation at the temperature $70^{\circ} \mathrm{C}$ in the laboratory holding oven

\begin{tabular}{|c|c|c|}
\hline \multirow{2}{*}{ time [days] } & \multicolumn{2}{|c|}{ Average $\mathrm{pH}$ of the solutions after incubation } \\
\cline { 2 - 3 } & CONS PET & BioPlaneta \\
\hline 0 & 6.7 & 6.7 \\
\hline 7 & 7.3 & 7.5 \\
\hline 14 & 6.0 & 7.5 \\
\hline 28 & 4.9 & 7.4 \\
\hline
\end{tabular}

During the experiments macroscopic observations of the surface changes were carried out and the weight loss was monitored. The changes of molecular weight and dispersity of the samples were analyzed by the Gel Permeation Chromatography, GPC, after the specified periods of degradation in both investigated environments, water and industrial composting.

\section{GPC Analysis}

The number-average molecular weight $\mathrm{Mn}$ and the dispersity $\mathrm{Mw} / \mathrm{Mn}$ of the investigated samples were estimated by GPC experiments conducted in the chloroform solution at $35^{\circ} \mathrm{C}$ and a flow rate of $1 \mathrm{ml} / \mathrm{min}$ using a Spectra-Physics 8800 solvent delivery system with two Mixed C Styragel columns in series and Shodex SE 61 refractive index detector. A volume of $10 \mathrm{ml}$ of sample solution in $\mathrm{CHCl} 3$ (concentration $0.5 \% \mathrm{w} / \mathrm{v}$ ) was injected. Polystyrene standards with low dispersity were used to generate the calibration curve.

\section{RESULTS AND DISCUSSION}

The hydrolytic degradation of polymer materials was carried out in vials with distilled water at the temperature $70^{\circ} \mathrm{C}$. During the process changes of average molecular weight of the investigated materials were determined by GPC measurements for different times of the degradation. The obtained data are presented in Figure 3. The results of GPC analysis showed shifts of unimodal traces to the lower values of molecular weight, which can suggest the decrease of molecular weight of the investigated samples.

The decrease of $\mathrm{pH}$ in solutions after CONS PET incubation, which accompanied the process, probably resulted from the appearance of low molecular acidic degradation products (Table 1 ).

The obtained results for the investigated materials before and after the degradation in the composting pile and in the container system are presented in Table 2 and Table 3.

A systematic decrease of molecular weight of the investigated samples was observed. The changes of molecular weight suggest that under the investigated composting conditions a hydrolytic degradation mechanism has oc- 


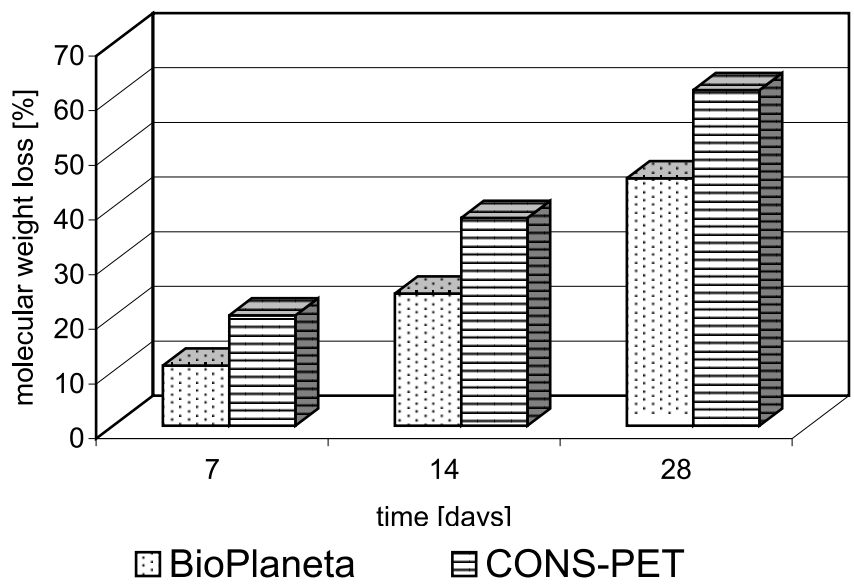

Figure 3. Molecular weight loss of the investigated materials before degradation and after degradation in distilled water at the temperature $70^{\circ} \mathrm{C}$

Table 2. Molecular weight loss of the investigated materials under the industrial composting conditions

\begin{tabular}{|c|c|c|c|c|}
\hline \multirow{3}{*}{ time [days] } & \multicolumn{4}{|c|}{ Molecular weight loss [\%] } \\
\cline { 2 - 5 } & \multicolumn{2}{|c|}{ CONS PET } & \multicolumn{2}{c|}{ BioPlaneta } \\
\cline { 2 - 5 } & $\begin{array}{c}\text { composting } \\
\text { pile }\end{array}$ & $\begin{array}{c}\text { container } \\
\text { system }\end{array}$ & $\begin{array}{c}\text { composting } \\
\text { pile }\end{array}$ & $\begin{array}{c}\text { container } \\
\text { system }\end{array}$ \\
\hline 7 & 25 & 4 & 22 & 7 \\
\hline 21 & 40 & 20 & 31 & 17 \\
\hline
\end{tabular}

curred. The macroscopic observations ("date not shown") demonstrate the disintegration of all the investigated samples, which corresponds to the weight loss results presented in Table 3.

Table 3. Weight loss of the investigated materials under the industrial composting conditions

\begin{tabular}{|c|c|c|c|c|}
\hline \multirow{2}{*}{ time [days] } & \multicolumn{4}{|c|}{ Average weight loss [\%] } \\
\cline { 2 - 5 } & \multicolumn{2}{|c|}{ CONS PET } & \multicolumn{2}{c|}{ BioPlaneta } \\
\cline { 2 - 5 } & $\begin{array}{c}\text { composting } \\
\text { pile }\end{array}$ & $\begin{array}{c}\text { container } \\
\text { system }\end{array}$ & $\begin{array}{c}\text { composting } \\
\text { pile }\end{array}$ & $\begin{array}{c}\text { container } \\
\text { system }\end{array}$ \\
\hline 7 & 4 & 6 & 3 & 1 \\
\hline 21 & 20 & 9 & 6 & 2 \\
\hline
\end{tabular}

\section{CONCLUSION}

The data suggest that the CONS-PET and BioPlaneta packaging materials are degradable while composting (biotic degradation, (bio)degradation) and during incubation in distilled water at $70^{\circ} \mathrm{C}$ (abiotic degradation). The decrease of molecular weight favours the hydrolytic mechanism of the material degradation process

\section{ACKNOWLEDGEMENT}

The research is supported by the European Regional Development Fund: Contract no. POIG.01.03.01-00-018/ 08.

\section{LITERATURE CITED}

1. Kikolski, P., Dłuska-Smolik, E. \& Bolińska, A. (2005). Method of assessment of polymers biodegradability for investigation of their usability to organic recovery by composting. Polimery, 50 (3), 208-212 (in Polish).

2. Żakowska, H. (2002). Packaging wastes. Warszawa, COBRO (in Polish).
3. Adamus, G., Dacko, P., Musioł, M., Sikorska, W., Sobota, M., Biczak, R., Herman, B., Rychter, P., Krasowska, K., Rutkowska, M. \& Kowalczuk M. (2006). Degradation of selected synthetic polyesters in natural conditions. Polimery, 51, 539-546 (in Polish).

4. Sikorska, W., Dacko, P., Sobota, M., Rydz, J., Musioł, M. \& Kowalczuk, M. (2008). Degradation Study of Polymers from Renewable Resources and their Compositions in Industrial Composting Pile. Macromol. Symp., 272, 132-135 DOI: 10.1002/masy.200851219.

5. Rutkowska, M., Krasowska, K., Heimowska, A. \& Kowalczuk, M. (2003). Degradation of the blends of natural and synthetic copolyesters in different natural environments. Macromol. Symp., 197, 421-429 DOI: 10.1002/masy.200350736 .

6. Yang, H. S., Yoon, J.S. \& Kim, M.N. (2004). Effects of storage of a mature compost on its potential for biodegradation of plastics. Polym. Degrad. Stab., 84 (3), 411-417 DOI: 10.1016/j.polymdegrastab.2004.01.014.

7. Kowalczuk, M. (2010) Paradigm of (bio)degradable polymers. Recykling, 2 (110) (in Polish).

8. Dacko, P., Rydz, J., Sikorska, W., Sobota, M. \& Kowalczuk, M. (2008). Organic recycling of materials base on polymers from renewable resources. Problemy ekologii, 1, 39 (in Polish).

9. Sikorska W., Rydz, J., Sobota, M., Dacko, P., Kowalczuk, M. \& Paradysz, W. (2009). Recycling of packaging materials under industrial composting condition. Technical Transactions. Mechanics, 106 (1-M), 313-316 (in Polish). 